\title{
Importancia del equilibrio ácido-base en la salud a partir de la alimentación
}

\section{Health importance of the acid-base balance as from food}

\author{
Héctor Ulises Bernardino-Hernández y Arturo Zapién-Martínez ${ }^{1 *}$
}

Fecha de recepción: 17 de enero de 2019

Fecha de aceptación: 6 de marzo de 2019

\begin{abstract}
Resumen - La alimentación se ha vuelto un tema de interés debido a los múltiples problemas de salud relacionados con la dieta que se han registrado en los últimos años. Alimentarse correctamente no es necesariamente seguir una larga lista de prohibiciones, sólo se requiere conocer aquellos alimentos que pueden satisfacer de forma correcta los nutrientes que el cuerpo humano necesita. El equilibrio del pH es fundamental para tener un óptimo estado de salud, pues al haber un aumento de acidez, el organismo activa diferentes sistemas para proteger las células y tejidos sanos. Sin embargo, una dieta desbalanceada provoca exceso de acidez que el organismo no puede neutralizar, lo que altera el buen funcionamiento de las células. El presente documento describe la relación de dicho equilibrio con la alimentación y sus posibles efectos en la salud.
\end{abstract}

\section{Palabras clave:}

Alimentación, dieta alcalina, equilibrio ácido-base, pH.
Abstract - Food and nutrition have become a topic of interest due to the multiple health problems related to diet that have developed in recent years. Eating correctly is not necessarily following a long list of prohibitions, it is only necessary to know which food can correctly fulfill the nutrients that the human body needs. The $\mathrm{pH}$ balance is fundamental to have an optimal health, because when there is an increase in acidity, the body activates different systems to protect healthy cells and tissues. However, an unbalanced diet causes an excessive acidity that the human body cannot neutralize, which alters the proper cell functioning. The present paper describes the relationship of the acid-base balance with nourishment and its possible effects on health.

\section{Keywords:}

Feeding, alkaline diet, acid-base balance, $\mathrm{pH}$.

${ }^{1}$ Facultad de Ciencias Químicas, Universidad Autónoma "Benito Juárez" de Oaxaca. Av. Universidad s/n, colonia Cinco Señores, C.P. 68120, 0axaca, México. *Correo electrónico: zaarma@yahoo.com 


\section{Equilibrio ácido-base y su importancia}

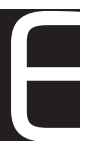
I término pH (potencial de hidrógeno) se usa para indicar la actividad y concentración de iones de hidrógeno en un fluido; es decir, es su medida de acidez o alcalinidad (Zavala, 2008). La escala va del 0 (sustancias ácidas) al 14 (sustancias alcalinas o básicas), pasando por el 7, que representa la neutralidad. El ser humano se encuentra en contacto con diversas sustancias en su entorno ambiental que presentan distintos $\mathrm{pH}$ y el mismo cuerpo contiene fluidos que tienen diferentes $\mathrm{pH}$, con los que funciona de manera normal y correcta. Cambios de $\mathrm{pH}$ en el organismo pueden alterar el desempeño de los órganos y aparatos, manifestándose en diversas enfermedades (figura 1 ).

En Alemania, en el año 2000, Jürgen Vormann reunió a científicos de todo el mundo para documentar el impacto de la acidosis metabólica sobre la salud, en particular la de los huesos y el crecimiento en la edad infantil. A partir de dicho evento se inició la conexión del pH con la salud; en especial, el proceso conocido como equilibrio ácido-base, que es un mecanismo de regulación del cuerpo humano para mantener el equilibro interno de la acidez o alcalinidad de los fluidos corporales y con ello procurar el correcto funcionamiento celular, por ende, la salud del individuo. Dicho mecanismo mantiene el equilibrio de $\mathrm{pH}$ mediante amortiguadores fisiológicos² (Mendoza, 2008), así como la compensación respiratoria ${ }^{3}$ y la compensación renal ${ }^{4}$ (Aristizábal-Salazar, Calvo-Torres, Valencia-Arango, Montoya-Cañon, Barbosa-Gantiva e Hincapié-Baena, 2015).
Los ácidos y las bases ingresan continuamente a la sangre procedentes del metabolismo ${ }^{5}$ normal de las células que conforman al individuo, de la dieta, ${ }^{6}$ de cualquier sustancia que se ingiera, por vía parenteral, dérmica, digestiva o a través de las mucosas (por ejemplo, medicamentos, drogas, alcohol, humo de tabaco, entre otros), así como provenientes de procesos patológicos (enfermedades como la diabetes mellitus, sepsis, gastroenteritis, obstrucción intestinal, por mencionar algunas). Dichas sustancias, según sus características, son amortiguadas por los sistemas tampón y eliminadas por el sistema pulmonar a través de la respiración y/o el renal mediante la orina. El sistema de tampones actúa instantáneamente, el sistema pulmonar lo hace en cuestión de minutos y dura algunas horas, mientras que el renal actúa en horas y tarda algunos días. Todos los procesos interactúan entre ellos para preservar el equilibrio interno del $\mathrm{pH}$ en el cuerpo humano. Si dichos canales fallan, ocurren cambios en el $\mathrm{pH}$ de los fluidos corporales, provocando cambios en las funciones celulares a nivel de la actividad de proteínas y enzimas en diferentes procesos metabólicos (glucólisis, gluconeogénesis, mitosis, síntesis de ADN, entre otros).

\section{La alimentación y el equilibrio ácido-base}

En una persona sana el $\mathrm{pH}$ de la sangre debe estar entre 7.35 y 7.45 , es decir, ligeramente alcalino para que las células funcionen correctamente. Los alimentos que se ingieren pueden ser ácidos o alcalinos e influir en el pH de los fluidos corporales,

\footnotetext{
2 También conocidos como sistemas tampón o buffer, que funcionan evitando cambios bruscos de pH en una solución, al añadir una base o un ácido. Entre ellos se encuentran ciertas proteínas intracelulares como la hemoglobina (muy abundante en el interior de los eritrocitos de la sangre), los fosfatos intracelulares, los huesos y el sistema bicarbonato/ácido carbónico (intracelular y extracelular). Dichos sistemas están interrelacionados y se amortiguan unos a otros.

${ }^{3}$ Conocido como mecanismo de regulación respiratoria relacionada con la ventilación pulmonar y que normaliza la concentración de $\mathrm{CO}_{2}$ en sangre arterial, aumentando o reduciendo la eliminación de $\mathrm{CO}_{2}$ en pulmones (hiperventilación o hipoventilación, respectivamente).

${ }^{4}$ También llamado mecanismo de regulación renal relacionada con la filtración renal, es la principal vía de eliminación de ácidos y bases producto del metabolismo normal y de los metabolitos ácidos patológicos del cuerpo, gracias a su capacidad de reabsorber y generar bicarbonato de modo variable en función del $\mathrm{pH}$ de las células tubulares renales.

${ }^{5}$ Se llama metabolismo al conjunto de reacciones químicas que ocurren en el interior de las células, que involucra la ruptura de biomoléculas para obtener energía (catabolismo) y la síntesis de biomoléculas a partir de moléculas sencillas (anabolismo).

${ }^{6}$ La dieta está formada por carbohidratos, lípidos y proteínas. El metabolismo de los dos primeros produce grandes cantidades de $\mathrm{CO}_{2}$ que se eliminan por los pulmones; en tanto, el metabolismo del tercer grupo genera ácidos no volátiles, que son amortiguados por el sistema bicarbonato/ácido carbónico de la sangre y son excretados por los riñones a través de la orina (Jajoo, Song, Rasmussen, Harris y Hughes, 2006).
} 
especialmente en el de la sangre. El equilibrio del $\mathrm{pH}$ es fundamental para contar con un óptimo estado de salud, ya que lo contrario da lugar a un ambiente interno propicio para la aparición de enfermedades. Una dieta adecuada puede mantener un pH idóneo que permita un normal funcionamiento del organismo y así disminuir el riesgo de adquirir padecimientos.

Diversos alimentos, una vez que son digeridos y metabolizados, provocan un efecto ácido en el cuerpo, mientras que otros actúan como agentes alcalinizantes que pueden neutralizar dichos ácidos. La dieta moderna es abundante en alimentos ricos en carbohidratos (harinas y azúcares refinados como galletas, panecillos, golosinas, repostería, comida rápida [pizzas, hot dogs], refrescos, bebidas energizantes y alcohólicas, entre otros), proteínas (alimentos de origen animal y sus derivados: carnes, embutidos, productos lácteos) y lípidos (grasas y aceites), así como en edulcorantes, colorantes y aditivos artificiales. Todos ellos -sobre todo si son alimentos procesados o industrializados- producen un aumento de la acidez producto de su metabolismo. Entonces, una dieta rica en carga ácida provocará a largo plazo condiciones de acidosis metabólica crónica, con las consecuentes alteraciones en numerosas funciones del organismo.

Cuando la persona se acidifica, la respuesta del cuerpo es ceder ciertos minerales para neutralizar los ácidos generados, de manera particular el calcio, provocando una descalcificación. Esta desmineralización afecta a cualquier órgano, especialmente a huesos y dientes, trayendo problemas en los sistemas donde están asociados. Si la dieta es constante y frecuentemente ácida, puede convertirse en un problema de acidez crónica que ocasiona algunos de los siguientes efectos (Frassetto, Morris, Sellmeyer y Sebastian, 2008):

a) Los huesos se descalifican, por lo que pierden resistencia y flexibilidad, pudiendo fracturarse más fácilmente. b) Los dientes se vuelven frágiles, quebradizos y más sensibles a los cambios de temperatura de los alimentos, promoviendo la aparición de caries. c) Un pH ácido interfiere con la absorción de minerales, por ello la absorción de calcio se torna ineficiente.

d) Un exceso de acidez influye en la aparición de ataques cardiacos, envejecimiento prematuro y obesidad.

e) El cuerpo genera colesterol (depósitos de grasa) para proteger la acumulación de residuos ácidos cristalizados fuera de los órganos vitales, como el hígado, corazón y riñones.

f) Puede presentarse cansancio generalizado, pérdida de tejido muscular, degeneración de articulaciones, debilitamiento del folículo capilar (pérdida de cabello), cálculos de riñón, problemas digestivos como gastritis, uñas frágiles y quebradizas, anemia, así como el ataque de agentes patógenos oportunistas como Candida albicans e infecciones respiratorias recurrentes, entre otras consecuencias.

g) Al comenzar el proceso de acidificación del organismo, también se presentan problemas como acné, ansiedad, ataques de pánico, depresión premenstrual, cólicos menstruales y premenstruales, congestión nasal crónica, diarrea, dificultad para levantarse en las mañanas, dolor muscular y de cabeza, estreñimiento, falta de deseo sexual, lengua blanca, manos y pies fríos, mareos y orina con un olor fuerte.

\section{Una dieta más saludable}

LLamentablemente, la dieta a nivel mundial ha evolucionado hacia la acidez (Cordain, Eaton y Sebastian, 2005), por lo que la gastronomía mexicana y oaxaqueña, así como las costumbres regionales y locales de la población, no se han quedado al margen de estos cambios, debido al fenómeno de industrialización y globalización de alimentos y a la adopción de estilos de vida poco saludables. La dieta en general se centra 
en el consumo de granos y productos de origen animal (precursores de ácidos) y una ingesta deficiente de frutas y vegetales (precursores de bases o álcalis). Para tener una alimentación saludable es recomendable iniciar un cambio en los hábitos, con las siguientes sugerencias (Suthar y Verma, 2014):

Incluir en la dieta alimentos más alcalinos:

1. Consumir diariamente abundantes frutas (así como sus jugos) y verduras de preferencia crudas, ya que la mayoría son alcalinizantes debido a la diversidad y cantidad de minerales que poseen.? Es necesario aclarar que hay alimentos con $\mathrm{pH}$ bajo (o sea, son ácidas fuera del organismo y al paladar), pero cuando el alimento se metaboliza genera una reacción alcalina y eleva el pH del cuerpo por encima de 7.0 (Jaffe, 2013), tal es el caso del limón. ${ }^{8}$

2. Reducir el consumo de verduras hervidas, pues $40-60 \%$ de los minerales y $95 \%$ de las vitaminas y bases que contienen las verduras se pierden en el agua de cocción, por lo que su contenido de bases disminuye. Una alternativa es cocer las verduras al vapor por lapsos cortos.

3. Consumir el líquido de las verduras en caldos, ya que conservan un porcentaje alto del valor terapéutico proveniente de sus minerales alcalinos, de ahí que ayudan a reestablecer el equilibrio ácido-base en enfermos y convalecientes. Un buen consejo es ingerir caldo de papa al menos una o dos veces a la semana.

Disminuir los alimentos considerados como ácidos:

1. Reducir el consumo de proteínas de origen animal (carnes, embutidos y lácteos) y sustituirlos por proteínas de origen vegetal, como espinacas, almendras, nueces, lentejas y legumbres, debido a que poseen cantidades importantes de azufre, fósforo y cloro.

2. Evitar el consumo de alimentos ricos en carbohidratos y grasas procesadas (industrializados), así como fritos, tales como bollería, galletas y bebidas gaseosas.

3. Otras recomendaciones para mantener un $\mathrm{pH}$ alcalino son consumir la sal de grano libre de aditivos (fluoroyodada), beber abundante agua natural, no fumar, no abusar en el consumo de bebidas alcohólicas, hacer ejercicio con regularidad de no muy alta intensidad para evitar la producción de ácido láctico, dormir bien y evitar el uso de medicamentos ácidos como la aspirina, entre otras drogas. En el caso de café y té, tratar de consumir en lo posible los que sean descafeinados.

\section{El equilibrio ácido-base y la manifestación de enfermedades}

Como ya se mencionó anteriormente, la carga ácida de la dieta está determinada por el balance entre alimentos formadores de ácidos y los formadores de bases. Para medir dicha carga se han desarrollado diversas ecuaciones matemáticas; una de las más aceptadas y utilizadas es el cálculo de la Carga Ácida Renal Potencial (CARP) (Remer y Manz, 1994), que se determina a partir de la clasificación de las CARP de los alimentos, que pueden poseer una carga ácida negativa o positiva, es decir, alcalinizantes o acidificantes del organismo, lo cual permite predecir la acidosis o alcalosis metabólica que inducen. Una dieta con CARP negativa producirá alcalosis metabólica, esto es, cuando se consumen

\footnotetext{
${ }^{7}$ Minerales formadores de álcalis (bases): potasio, sodio, calcio, magnesio, hierro, manganeso, cobre, litio, zinc. Minerales formadores de ácidos: azufre, fósforo, cloro, silicio, flúor, iodo, bromo (Paulev y Zubieta-Calleja, 2005).

${ }^{8}$ Existe la creencia de que el jugo o bebidas a base de limón pueden dañar los dientes, sin embargo, no se ha asociado a un daño de la capa dental. Si una persona bebe una gran cantidad de jugo de limón de forma rutinaria, no causa caries o daños en la dentadura como sí lo hace el consumo de una gran cantidad de alimentos procesados como los dulces, pasteles, galletas, chocolates y caramelos. Como ejemplo, el limón contiene una diversidad de minerales (calcio $=12 \mathrm{mg}$, zinc= $0.12 \mathrm{mg}$, cloro= $4.5 \mathrm{mg}$, flúor=10 $\mu$ g, fósforo=16 mg, hierro=0.4 mg, yodo=3 mg, magnesio= $18 \mathrm{mg}$, manganeso= 0.04 mg, potasio=149 mg, selenio=1 ug y sodio=3 mg) (Moreiras, Carbajal, Cabrera y Cuadrado, 2011), responsables de elevar la alcalinidad en el organismo.
} 
alimentos alcalinizantes; o bien, acidosis en caso de ser positiva, cuando se ingieren mayoritariamente alimentos ácidos (Remer, 2000).

Entonces, la orina puede tener un $\mathrm{pH}$ variable de ácido a alcalino, dependiendo de la necesidad de equilibrar el ambiente interno, por lo que es un índice relativamente muy bueno de la acidez corporal. En el cuadro 1 se presentan los valores de CARP de distintos alimentos, que pueden ser útiles para considerar incluirlos en la dieta diaria.

Si un individuo sigue malos hábitos de alimentación con carga elevada de ácidos, provocará un esfuerzo excesivo en la función eliminadora de los riñones, pudiendo afectar su funcionamiento. ${ }^{9}$ Al respecto, Passey (2017) indica que la reducción de la carga ácida a partir de una dieta baja en proteínas animales con un aumento de proteínas vegetales, así como la ingesta alta de frutas y verduras, retrasa la progresión de la enfermedad renal crónica, incluso mejora la función renal, mientras mantiene el estado nutrimental del individuo.

Hasta el momento no hay evidencias sólidas que demuestren una relación directa entre los ácidos inducidos por la dieta y la manifestación de cáncer. Sin embargo, Robey (2012) menciona que se ha comprobado que el desequilibrio ácido-base influye en la actividad molecular a nivel celular promotora de la carcinogénesis, es decir, incentiva la formación, aparición y/o progresión de tumores. Entonces, una acidosis inducida por la dieta puede ser un desencadenante potencial o indirecto de una cascada multifactorial de eventos moleculares asociados a la carcinogénesis, pero es necesario obtener evidencias científicas, ya que la dieta no es el único factor asociado al desequilibrio ácido-base y al riesgo de padecer un cáncer, también influyen los antecedentes genéticos de la persona, la exposición a agentes físicoquímicos y biológicos, y el estado inmunológico y patológico. Al respecto, la obesidad o el síndrome metabólico están relacionados con una dieta acidogénica, vinculado a la resistencia a la insulina y al estado proinflamatorio, elevando el riesgo de cáncer (Hursting y Berger, 2010).

Hernández-Ramírez y López-Carrillo (2014) refieren que el cáncer gástrico (CG) está vinculado, además de la infección por Helicobacter pylori, a una dieta baja en frutas y vegetales no feculentos y allium (ajos, cebollín, puerros, cebolla) y ricos en selenio, así como un alto consumo de sal, alimentos salados, en salmuera y ahumados, chile, carnes procesadas y asadas o a la parrilla, además de consumo de tabaco y alcohol. Todos éstos presentan propiedades acidogénicas y valores positivos de CARP, por lo que una dieta alcalina podría ser utilizada para evaluar programas de prevención primaria para dicho padecimiento.

Finalmente, Schwalfenberg (2012) afirma que la dieta alcalina produce una orina alcalina y puede reducir su contenido de calcio, pero no necesariamente refleja el balance total de este mineral, por lo que no hay evidencia de que esta dieta mejore la salud ósea o proteja de la osteoporosis. No obstante, sí está documentado que una dieta alcalina rica en frutas y verduras proporciona una cantidad considerable de minerales que mejoran la proporción potasio/sodio, lo cual disminuye el desgaste muscular y mitiga los efectos de la hipertensión y los accidentes cerebrovasculares. Además de elevar las concentraciones de magnesio intracelular que interviene en diversos procesos enzimáticos, entre ellos la activación de la vitamina $D$, que impacta en el equilibrio fosfocálcico y el metabolismo del sistema óseo.

\section{Conclusión}

A manera de conclusión y de acuerdo con lo antes expuesto, una dieta alcalina rica en alimentos con CARP negativos puede influir en el equilibrio ácido-base de una persona, pero es necesario realizar más estudios que documenten sus efectos benéficos en el control y/o prevención de diversas enfermedades. Es muy importante generar y mantener una dieta balanceada y

9 Una tercera parte del total de desechos ácidos del cuerpo se elimina a través de los pulmones, las dos terceras partes mayoritariamente son eliminadas por los riñones, y pequeñas cantidades por la piel y los intestinos. Aproximadamente 6 litros de sangre son filtrados por los riñones cada siete minutos con el fin de eliminar los productos de desecho que no pueden eliminarse en forma de gas a través de los pulmones. 
diversa, que incluya diariamente el consumo adecuado de todos los grupos de alimentos, particularmente frutas y verduras, evitando comida industrializada (harinas refinadas y carnes procesadas). También es conveniente mencionar que no es recomendable abusar de algún grupo de alimentos en particular, ya que podría acarrear resultados negativos hacia la salud.

Es necesario promover una educación nutricional entre la población, particularmente en la infantil y juvenil, a fin de garantizar el buen desarrollo de las personas y prevenir posibles enfermedades en la edad adulta. Para la población en general que enfrenta desequilibrios ácido-base y que pudiesen estar relacionados con inadecuados hábitos de alimentación, es posible implementar y evaluar estrategias de corrección hacia dietas más saludables considerando la CARP de los alimentos. Lo anterior podría abonar a la generación de evidencias sobre los beneficios que promueve una dieta alcalina, la cual -junto con otras recomendaciones como hacer ejercicio y evitar el consumo de tabaco y alcohol- puede coadyuvar en la prevención y/o retraso de la manifestación de diversas enfermedades, así como el mejoramiento y protección de la salud. La finalidad es elevar la calidad de vida de la población.

\section{Referencias}

Aristizábal-Salazar, R. E., Calvo-Torres, L. F., ValenciaArango, L. A., Montoya-Cañon, M., Barbosa-Gantiva, 0. e Hincapié-Baena, V. (2015). Equilibrio ácido-base: el mejor enfoque clínico. Revista Colombiana de Anestesiología,43(3),219-224.Disponibleenhttps:// www.redalyc.org/pdf/1951/195140440007.pdf

Cordain, L., Eaton, S. B. y Sebastian, A. (2005). Origins and evolution of the Western diet: health implications for the 21st century. Am J Clin Nutr., 81(2), 341-354. Disponible en https://academic. oup.com/ajcn/article/81/2/341/4607411
Frassetto, L. A., Morris, R. C., Sellmeyer, D. E. y Sebastian, A. (2008). Adverse effects of sodium chloride on bone in the aging human population resulting from habitual consumption of typical american diets. Nutr., 138(2), 419-422. Disponible en https://academic.oup.com/jn/article/138/2/419S/4665073

Hernández-Ramírez, R. U. y López-Carrillo, L. (2014). Dieta y cáncer gástrico en México y en el mundo. Salud Pública de México, 56(suplemento X), 555-560. Disponible en https://www.redalyc.org/ pdf/106/10632373018.pdf

Hursting, S. D. y Berger, N. A. (2010). Energy balance, host-related factors and cancer progression. J Clin Oncol., 28(26), 4058-4065. Disponible en http://ascopubs.org/doi/10.1200/JC0.2010.27.9935

Jaffe, R. (2013). The alkaline way in digestive health. En R. R. Watson y V. R. Preedy (eds.), Bioactive foods as dietary interventions for liver and gastrointestinal disease (pp. 1-21). San Diego: Academy Press, Elsevier Inc.

Jajoo, R., Song, L., Rasmussen, H., Harris, S. S. y Hughes, B. D. (2006). Dietary acid-base balance, bone resorption, and calcium excretion. J Am CoIleg Nutr, 25(3), 224-230. Disponible en https:// pdfs.semanticscholar.org/4234/662c2e78b6f39b339539c77a297180736e08.pdf

Mendoza, M. A. (2008). Funcionamiento e importancia del sistema bicarbonato/CO2 en la regulación del pH sanguíneo. Ciencia Ergo Sum, 15(2), 155-160. Disponible en https://www.redalyc.org/ pdf/104/10415206.pdf

Moreiras, O., Carbajal, A., Cabrera, L. y Cuadrado, C. (2011). Tablas de composición de alimentos. México: Ed. Pirámide. 
Passey, C. (2017). Reducing the dietary acid load: how a more alkaline diet benefits patients with chronic kidney disease. Journal of Renal Nutrition, 27(3), 151-160. Disponible en https://www.jrnjournal.org/article/S1051-2276(16)30188-1/ fulltext

Paulev, P. E. y Zubieta-Calleja, G. R. (2005). Essentials in the diagnosis of acid-base disorders and their high altitude application. J Physiol Pharmacol, 56(Suppl. 4), 155-170. Disponible en http://zuniv. net/pub/Acid-Base.pdf

Remer, T. (2000). Influence of diet on acid-base balance. Seminars in Dialysis, 13(4), 221-226. Disponible en https://pdfs.semanticscholar.org/0593/ 2125190ffdc90220f21cf704d1aa8296c893.pdf

Remer, T. y Manz, F. (1994). Estimation of the renal net acid excretion by adults consuming diets containing variable amounts of protein. Am J Clin Nutr., 59(6), 1356-1361. Disponible en https://academic.oup. com/ajcn/article-abstract/59/6/1356/4715881?redirectedFrom=fulltext
Robey F. (2012). Examining the relationship between diet-induced acidosis and cancer. Nutrition \& Metabolism, 9(72). Disponible en https:// nutritionandmetabolism.biomedcentral.com/track/ pdf/10.1186/1743-7075-9-72

Schwalfenberg, G. K. (2012). The alkaline diet: Is there evidence that an alkaline $\mathrm{pH}$ diet benefits health? Journal of Environmental and Public Health, 2012, 1-7. Schwalfenberg G. K. (2011). doi:10.1155/2012/727630

Suthar, N. N. y Verma, A. P. (2014). Alkaline diet and health-a brief review. International Journal of Basic \& Applied Physiology, 3(1), 22-30. Disponible en http:// ijbap.weebly.com/uploads/1/3/1/4/13145127/2.review.pdf

Zavala C., G. G. (2008) Una visión universitaria: el pH, sustento en el equilibrio químico para la vida celular. CienciaUAT, 2(4), 62-66. Disponible en https://www. redalyc.org/articulo.oa?id=441942912004 


\section{Figura 1.}

Ejemplos de fluidos y su correspondiente $\mathrm{pH}$

\begin{tabular}{|c|c|c|}
\hline Ejemplo & $\mathrm{pH}$ & Beneficio biológico en el cuerpo humano \\
\hline $\mathrm{HCl}(1.0 \mathrm{M})$ & $\approx 1$ & 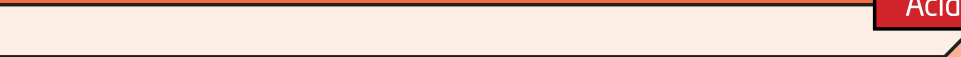 \\
\hline Jugos gástricos & $\approx 1.3-3.5$ & Favorece la digestión de alimentos \\
\hline Jugo de limón & 2.3 & \\
\hline Vinagre & 2.9 & \\
\hline Bebidas carbonatadas (refrescos de cola) & $\approx 3.0$ & \\
\hline Vino tinto & 3.5 & \\
\hline Jugo de naranja & $3.5-4.5$ & \\
\hline Jugo de tomate & $\approx 4.2$ & \\
\hline Cerveza & $\approx 4.5$ & \\
\hline Café & $\approx 5$ & \\
\hline Lluvia ácida & $1.5-5.5$ & \\
\hline Luvia no contaminada & $5.5-6.5$ & \\
\hline Piel & $\approx 4.5-6.5$ & Protección frente a agentes patógenos \\
\hline Vagina & $\approx 4.7$ & Mantiene el equilibrio de la flora bacteriana \\
\hline Sudor & $4-8$ & Eliminación de toxinas y regulación de la temperatura corporal \\
\hline Orina humana & $\approx 6.3-7.2$ & Está en función del equilibrio interno del cuerpo humano \\
\hline Leche de vaca & 6.4 & \\
\hline Saliva humana en reposo & 6.6 & \\
\hline Agua pura & $7.0(6-8)$ & \\
\hline Saliva humana durante las comidas & 7.2 & \\
\hline Sangre & 7.35-7.45 & Es constante para mantener el buen funcionamiento del cuerpo humano \\
\hline Líquidos intersticiales & 7.2-7.4 & Manterne un ambiente apropiado para las reacciones químicas \\
\hline Líquido cefalorraquídeo & $\approx 7.5$ & Amortiguador, protección inmunológica del cerebro \\
\hline Lágrimas & 7.4-7.7 & Humectar el ojo \\
\hline Bilis & $\approx 7.6-8.8$ & Neutraliza jugos gástricos y ayuda en la digestión \\
\hline Jugos pancreáticos & $\approx 8.8$ & Neutraliza jugos gástricos y ayuda en la digestión \\
\hline Agua de mar & $\approx 7.5-8.4$ & \\
\hline Paredes del estómago & $\approx 8$ & Protección de los jugos gástrico \\
\hline Bicarbonato de sodio (Alka seltzer) & 8.4 & \\
\hline Agua mineral & $\approx 9$ & \\
\hline Crema de dientes & 9.9 & \\
\hline Detergentes & $\approx 10$ & \\
\hline Leche de magnesia (antiácido) & 10.5 & \\
\hline Blanqueadores amoniacales comerciales & 11.5 & \\
\hline Limpiadores de cañerías & $13-14$ & \\
\hline $\mathrm{NaOH}(1.0 \mathrm{M})$ & 14 & \\
\hline
\end{tabular}


Cuadro 1.

Valores de CARP en diversos alimentos

\begin{tabular}{|c|c|c|c|}
\hline Alimento & $\begin{array}{c}\text { CARP * (mEq de: } \mathrm{Cl} 1-+ \text { PO43- + SO42- - Na1 + - K1+ - } \\
\text { Ca2 + - Mg2+ ) }\end{array}$ & Alimento & 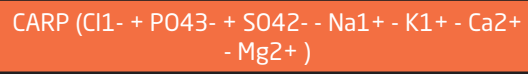 \\
\hline Queso manchego & +28.7 & Azúcar blanca & -0.1 \\
\hline Yema de huevo & +23.4 & Cerveza de barril & -0.2 \\
\hline Sardina en aceite & +13.5 & Miel & -0.3 \\
\hline Arroz integral & +12.5 & Té verde & -0.3 \\
\hline Salami & +11.6 & Espárragos & -0.4 \\
\hline Queso & +11.3 & Margarina & -0.5 \\
\hline Queso fresco & +11.1 & Pepino & -0.8 \\
\hline Carne de cordero & +9.9 & Jugo de uva & -1.0 \\
\hline Salmón & +9.4 & Azúcar integral & -1.2 \\
\hline Carne de ternera & +9.0 & Vino blanco & -1.2 \\
\hline Carne de pollo & +8.7 & Brócoli & -1.2 \\
\hline Harina de trigo integral & +8.3 & Café & -1.4 \\
\hline Cacahuates & +8.3 & Champiñones & -1.4 \\
\hline Huevos & +8.2 & Pimiento & -1.4 \\
\hline Carne vacuna & +7.8 & Mermeladas & -1.5 \\
\hline Bacalao & +7.1 & Cebolla & -1.5 \\
\hline Filete de bacalao & +7.1 & Agua mineral & -1.8 \\
\hline Leche entera & +7.0 & Sandía & -1.9 \\
\hline Nueces & +6.8 & Manzana & -2.2 \\
\hline Carne de cerdo & +6.7 & Fresas & -2.2 \\
\hline Salchichas & +6.7 & Vino tinto & -2.4 \\
\hline Espagueti & +6.5 & Lechuga & -2.5 \\
\hline Cereal de maíz & +6.0 & Limón & -2.6 \\
\hline Palomitas de maíz & +6.0 & Naranja & -2.7 \\
\hline Arroz blanco & +4.6 & Piña & -2.7 \\
\hline Almendras & +4.3 & Avellanas & -2.8 \\
\hline Pan de centeno & +4.1 & Jugo de naranja & -2.9 \\
\hline Pastel & +3.7 & Chicharos & -3.1 \\
\hline Pan blanco & +3.7 & Tomate & -3.1 \\
\hline Lentejas & +3.5 & Berenjenas & -3.4 \\
\hline Chocolate amargo & +2.4 & Cerezas & -3.6 \\
\hline Pan de trigo integral & +1.8 & Rábano & -3.7 \\
\hline Yogurt & +1.5 & Coliflor & -4.0 \\
\hline Clara de huevo & +1.1 & Papas & -4.0 \\
\hline Cerveza clara & +0.9 & Kiwi & -4.1 \\
\hline Leche desnatada & +0.7 & Calabacín & -4.6 \\
\hline $\begin{array}{l}\text { Leche entera } \\
\text { pasteurizada }\end{array}$ & +0.7 & Zanahoria & -4.9 \\
\hline Mantequilla & +0.6 & Apio & -5.2 \\
\hline Helado de vainilla & +0.6 & Plátano & -5.5 \\
\hline Coca cola & +0.4 & Espinacas & -14.0 \\
\hline Aceite de girasol & 0 & Higos secos & -18.1 \\
\hline Aceite de oliva & 0 & Uvas pasa & -21.0 \\
\hline
\end{tabular}

* CARP (carga ácida renal potencial) = (sulfato + cloruro + 1.8x fosfato + ácidos orgánicos) menos (sodio + potasio + 2x calcio + 2x magnesio). Fuente: Remer y Manz, 1994. 


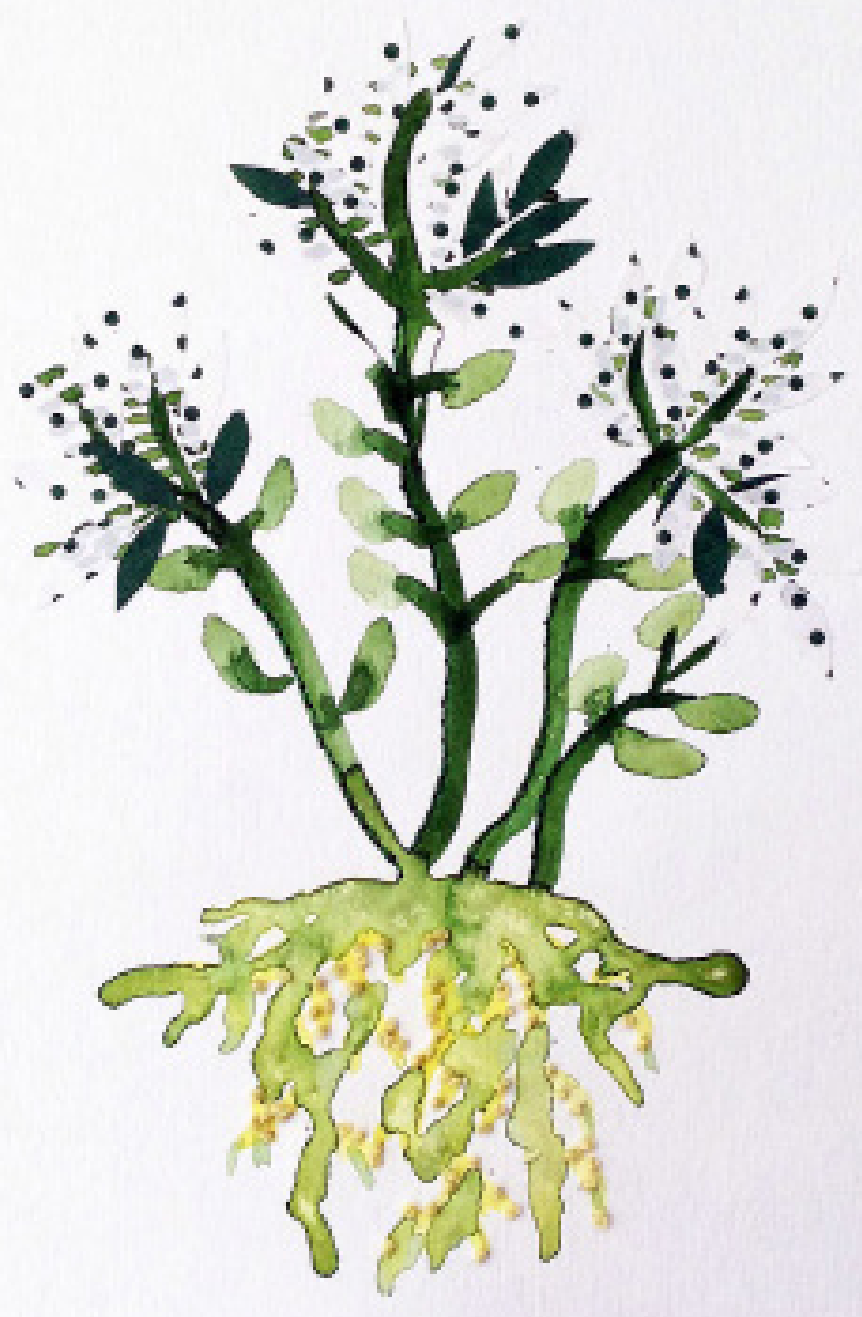

"Quetzalahuexotl krispy"

Acuarela, grana cochinilla, hilaza y

fragmentos de bolsa de producto

de consumo sobre papel.

$35 \times 27 \mathrm{~cm}$

2018

Smula faudival 9 zoip 